\title{
THE INTERNATIONAL CONFERENCE OF THE LEPROSY MISSION
}

\author{
Singapore, 1976
}

\author{
S. G. BROWNE
}

The Conference held in Singapore from 3 to 15 May, 1976 was something of an event. The last such Conference was held in Lucknow in 1953, which was well reported in an article by William Bailey that appeared in Leprosy in India (1954) 26, 53-62. The sulphones were just coming into practical therapeutics, and reconstructive surgery for the deformities of leprosy was beginning. The leaders of The Leprosy Mission, the oldest and the biggest voluntary agency concerned with leprosy, thought the time opportune in 1976 to take a hard look at present policies and future prospects, so as to utilize the resources of the Mission in the best possible ways for the benefit of the individual leprosy sufferer and the community of which he should form an integral part.

Gone are the days when custodial care for the favoured few in a context of Christian compassion was all that could be of fered to the "lepers in India". And impossibly distant seems the Second International Leprosy Conference at Bergen (in 1908 it was) when the learned participants listened spell-bound as a layman, Wellesley Bailey, the founder of the Mission, spoke out of the breadth of his experience and encouraged the medical scientists and the government physicians to tackle realistically the problem of leprosy. When the Congress agreed-and this was the only matter apparently on which they were agreed-that established leprosy was quite incurable, it was Bailey who detected a faint glimmer of hope. They did not know at the time that the year before, two German chemists, Fromm and Wittmann, had synthesized diamino-diphenyl sulphone.

The 1976 Conference drew over 90 invited participants from some 35 countries, representing the "Western" world (including Australia and New Zealand) in which most of the million and a quarter pounds sterling is now raised annually, and also a gratifying number of representatives from those countriesparticularly India-where the Mission expends the bulk of its money. Although doctors accounted for only a quarter of the invited participants, other members of the medical team-nurses, physiotherapists, occupational therapists, hospital administrators-were well to the fore, and regional secretaries and selected members of the Councils of various auxiliaries made up a knowledgeable and interested group.

As befits a Christian body concerned with compassionate caring as well as medical competence, the Conference studied in depth the changing role of the Mission as world medical opinion moved away from concentration on a single disease to community health and prevention. It was generally appreciated that although the Mission during the 102 years of its existence may have sought to isolate in thought and action the neglected victims of leprosy, and has stimulated governments and other voluntary agencies to take cognizance of the importance 
of leprosy in the community, yet its future role may change as it strives to ensure that the leprosy sufferer is accorded his rights as a citizen to social and medical justice. Thus, far from becoming redundant, the Mission will have a significant and continuing role to play in community health programmes. Its medically serious contribution is being increasingly recognized by governments faced not only with the backlog of deformity, but also with an intractable medico-social problem whose solution cannot be sought in purely therapeutic or surgical terms. It is in this respect that the dedicated and highly motivated team-member-from research scientists like Professor C. K. Job to the humblest paramedical worker-will be able for many years to come to contribute by precept and example to a government countrywide programme of leprosy treatment and control.

The Conference paid tribute to the pioneering endeavours of those associated with the Mission whose influence continues to be apparent in the world of leprosy, especially in the realms of compassionate caring for individuals hopelessly deformed and hence rejected by society; modern medicinal treatment with sulphones, clofazimine, rifampicin and the rest; reconstructive surgery; rehabilitation; integration of leprosy into community health programmes; insistence of the importance of the individual in the mass; the relevance of social, cultural and psychological factors in any scheme for leprosy control and treatment.

Far from resting upon the laurels of the pioneers, the Conference considered the challenge of the possibility of the emergence of sulphone-resistance on a wide scale and the financial implications of multi-drug therapy, the significance of persister leprosy bacilli, measures to counteract the transmission of leprosy in overcrowded communities, the place of reconstructive surgery and rehabilitation in a total programme of medical care where financial constraints are paramount, the necessity for overcoming social stigma and community cultural pressures, the need to conform to government directives while somehow retaining the initiative and flexibility characteristic of voluntary agencies, the opportunities for field and epide miological research, etc.

In addition to these medical concerns within The Leprosy Mission purview and responsibilities, the Conference discussed the promotional and educational aspects of its world-wide task. Far from being a mere fund-raising organization, The Leprosy Mission looks forward to increasing its impact for good on the problem of leprosy in many countries, bringing together the accumulated wisdom of the past, a youthful zest and enthusiasm, and a motivated service to the victims of leprosy.

The Conference expressed its disappointment that leprosy is a neglected subject in the curricula of many medical schools, even in countries where the disease is prevalent, and discussed ways in which the challenge of leprosy could be presented to students and interns, to nurses and physiotherapists: visits of roving lecturers (especially leprologists and reconstructive surgeons), the provision of transparencies and taped commentaries, the production of brochures and illustrated booklets, the encouragement of visits of medical students during their elective periods to leprosy centres, the utilization of the experience of consultants (particularly dermatologists and orthopaedic surgeons) who would after early retirement become available as lecturers and teachers, the granting of scholarships for impecunious medical students showing an interest in leprosy, etc. The Conference stressed the need to make medical folk in general aware of the sheer interest of leprosy today in the light of immunological and microbiological 
research, and the need for epidemiological investigations of comparable excellence and coverage. It is not only the clạallenge of case-finding, but the even more demanding task of case-holding that accounts for the failure of many leprosy control programmes.

As a Founder-Member of ELEP (now ILEP), The Leprosy Mission is conscious of the need to work together with other bodies pursuing similar objectives, and plays a very active part in joint activities. In the realm of publications, too, the Mission is becoming increasingly active, particularly in the production of material intended for medical auxiliaries and doctors.

If Lucknow 1953 indicated the way forward into effective chemotherapy and reconstructive surgery, Singapore 1976 may well mark the beginning of an era of sober consolidation of activities and a continuing mobilization of medical and non-material resources to face the common foe. 